\begin{tabular}{l} 
JOURNAL OF APPLIED MECHANICAL \\
ENGINEERING AND RENEWABLE \\
ENERGI (JAMERE) \\
ISAS Vol. 1 No. 1, Februari 2021. $20-23 \quad$ e-ISSN 2775-1031 \\
\hline
\end{tabular}

\title{
Rancang Bangun Alat Penyortir Beras Dengan Sistem Penggerak Motor Listrik
}

\author{
Teguh Catur Prambudi ${ }^{1}$, Laily Ulfiyah $^{2}$, Lukman Hadiwijaya ${ }^{3}$ \\ ${ }^{1,2,3}$ Teknik Mesin Alat Berat, Politeknik Negeri Madura \\ ${ }^{1}$ teguhcatur@gmail.com*, ${ }^{2}$ lailyulfiyah1@gmail.com
}

\begin{abstract}
Rice is the staple food most consumed by Indonesians which is produced from milling dry unhusked rice grain. In the dry unhusked rice grain milling process, rice has different forms, namely whole and cracked rice. This is due to the poor quality of the paddy rice. The different in forms has led to a different selling value. Whole rice is more expensive than the other. Therefore, sorting was done to obtain the differences. This study was carried out to build rice sorting device with a system in the form of a launch crank mechanism as a vibration system. This device has several components consisting of two mesh and two turnbuckle eye \& eye as the sieve tilt adjustment. In the tilt experiment, two variations of the angle were obtained, namely an angle of $10^{\circ}$ and an angle of $15^{\circ}$. This device uses a single-phase electric motor as the driving force of the launching crankshaft. The transmission system uses a pulley and a v-belt from a single-phase electric motor that is passed to the pulley. From the test results that have been carried out two-angle variations with a capacity of $10 \mathrm{~kg}$. At an angle of $15^{\circ}, 69 \%$ pure rice is obtained with less optimal results because the slope of the angle is too steep. Whereas at an angle of $10^{\circ}$, the yield of pure rice is $85 \%$ which has a less angular slope so that the sorting of rice is maximized.
\end{abstract}

Keywords: Sieve, rice, sorting device, variation of elevation angle

\begin{abstract}
Abstrak
Beras merupakan makanan pokok yang paling banyak dikonsumsi oleh masyarakat Indonesia yang dihasilkan dari penggilingan gabah kering. Pada proses penggilingan gabah kering terdapat beras yang berbeda bentuk yaitu beras utuh dan tidak utuh. Hal itu disebabkan oleh kualitas padi yang kurang bagus. Dari perbedaan bentuk beras memiliki nilai jual yang lebih tinggi. Beras yang utuh akan lebih mahal dibandingkan beras yang tidak utuh. Oleh karena itu dilakukan penyortiran untuk mendapatkan perbedaan beras. Penelitian ini membuat suatu alat penyotir beras dengan sistem berupa mekanisme engkol peluncur sebagai sistem getaran. Alat ini mempunyai beberapa komponen yang terdiri dari dua mesh dan dua buah turnbuckle eye \& eye sebagai pengaturan kemiringan ayakan. Dalam eksperimen kemiringan didapat dua variasi sudut yaitu sudut $10^{\circ}$ dan sudut $15^{\circ}$. Pada alat ini menggunakan motor listrik satu phase sebagai penggerak poros engkol peluncur. Sistem transmisi menggunakan pulley dan v-belt yang dari motor listrik satu phase yang diteruskan ke pulley. Dari hasil pengujian yang telah dilakukan variasi dua sudut dengan kapasitas $10 \mathrm{~kg}$. Pada sudut $15^{\circ}$ didapatkan beras murni $69 \%$ dengan hasil kurang maksimal karena kemiringan sudut terlalu curam. Sedangkan pada sudut $10^{\circ}$ didapatkan hasil beras murni $85 \%$ yang mempunyai kemiringan sudut lebih minim sehingga penyortiran beras lebih maksimal.
\end{abstract}

Kata kunci: Ayakan, Beras, Penyortir, Variasi Sudut Elevasi

\section{Pendahuluan}

Beras merupakan makanan pokok yang paling banyak dikonsumsi oleh masyarakat Indonesia. Menurut Survey Social Ekonomi Nasional 2009-2013 konsumsi beras di Indonesia mencapai 85.514 per kapita/tahun pada tahun 2013 (Kementrian Pertanian RI, 2013). Bahwa beras salah satu ke unggulan pertanian di Indonesia yang memiliki berbagai kualitas,antaranya butir utuh dan butir tidak utuh. Butir utuh adalah butirbutir yang utuh tidak ada yang patah sedangkan butir tidak utuh adalah butir yang tidak utuh dari keutuhannya.
Selain kualitas beras yang dapat memberikan nilai bagi konsumen adalah harga.

Harga beras yang butir utuh lebih mahal daripada butir yang tidak utuh. Karena beras yang utuh yang tidak ada patahanya akan lebih banyak saat ditanak. Selain itu warna yang putih dianggap penting karena beras lebih meningkatkan selera makan (Balai Pasar Padi, 2012). Untuk itu dibuat alat penyortir beras.

Pada studi sebelumnya penyortiran abu sekam padi mengunakan pengayak getar yang diuji adalah sebuah prototype pengayak getar yang terdiri dari empat buah 
pegas yaitu dua buah pegas di bagian depan dan dua dalam penampung yang sesuai volume penampung, pegas di bagian belakang serta dengan dua buah massa setelah itu tarik pintu penampung, kemudian beras akan yaitu sebuah saluran hasil ayakan dan sebuah ayakan turun kebawah ke sistem penyortiran .ayakan pertama yang mengunakan ukuran mesh tertentu ayakan yang untuk beras utuh sedangkan ayakan kedua untuk beras sesuai ukuran beras dan pegas [1]. Dari alat tersebut yang tidak utuh.

dimodifikasi dengan dua mesh, dua buah bearing di bagian samping ayakan, turnbuckle eye \& eye sebagai 3. Hasil dan Pembahasan Perencanaan Pulley pengatur sudut kemiringan ayakan dan engkol peluncur sebagai penggerak ayakan [2].

Data awal dari perencanaan pulley adalah sebagai

\section{Metode Penelitian}

\section{Desain Alat}

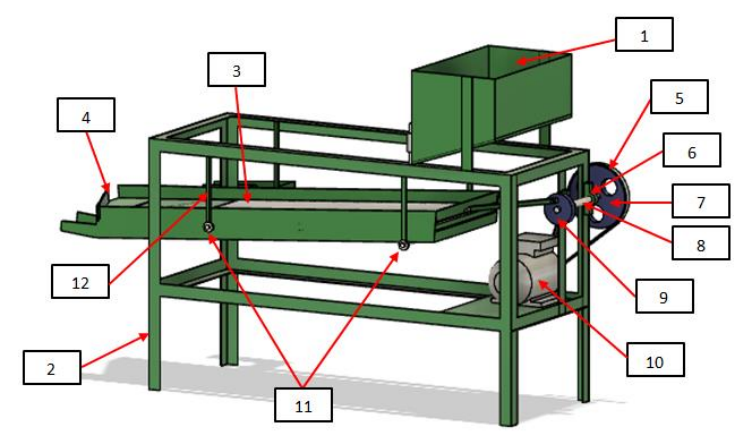

Gambar 1. Desain Alat

Keterangan

1. Wadah Penampung

2. Kerangka Utama

3. Mesh/Ayakan

4. Output ayakan

5. V-Belt

6. Bearing Duduk

7. Pulley

8. Poros

9. Poros Engkol

10. Motor Listrik

11. Roll Bearing

\section{Prinsip Kerja Alat Penyortir Beras}

Alat ini membuat suatu alat penyotir beras dengan sistem berupa mekanisme engkol peluncur sebagai sistem getaran. Alat ini mempunyai beberapa komponen yang terdiri dari dua mesh dan dua buah turnbuckle eye \& eye sebagai pengaturan kemiringan ayakan. Dalam eksperimen kemiringan didapat dua variasi sudut yaitu sudut $10^{\circ}$ dan sudut $15^{\circ}$. Pada alat ini menggunakan motor listrik satu phase sebagai penggerak poros engkol peluncur. Sistem tranmisi menggunakan pulley dan vbelt yang dari motor listrik satu phase yang diteruskan ke pulley.

Prinsip kerja alat penyortir beras, putaran motor listrik menggerakan pulley melalui V-belt yang seporos dengan poros engkol peluncur, kemudian putaran poros engkol peluncur menggerakkan kerangka ayakan. setelah poros engkol peluncur berputar dan ayakan akan bergerak maju mundur, kemudian tuangkan beras ke berikut: [3]

a. Diameter Pulley penggerak $\left(d_{\mathrm{p}}\right)=70 \mathrm{~mm}$

b. Diameter pulley yang digerakkan $\left(D_{\mathrm{p}}\right)=300 \mathrm{~mm}$

c. Daya motor listrik $1 \mathrm{HP}=746$ watt $=0,746 \mathrm{~kW}$ dengan putaran $1400 \mathrm{rpm}$.

d. Dengan menggunakan persamaan 2.14, diameter driven dapat dihitung sebagai berikut :

$$
\begin{aligned}
& \frac{d_{p}}{D_{p}}=\frac{n_{2}}{n_{1}} \\
& \frac{75}{300}=\frac{n}{1400} \\
& 300 \mathrm{n}=70 \times 1400 \\
& \mathrm{n}=\frac{98.000}{300} \\
& \mathrm{n}=326,666 \mathrm{rpm}
\end{aligned}
$$

Lebar pulley dapat dihitung dengan:

$$
\begin{aligned}
& \mathrm{B}=\mathrm{Lebar} \text { pulley }(\mathrm{mm}) \\
& n=\mathrm{Jumlah} \text { alur pada pulley }(\mathrm{mm}) \\
& e=\mathrm{Jarak} \text { alur pulley dengan sisi luar pulley }(\mathrm{mm}) \\
& \mathrm{B}=(n-1) \cdot e+2 . e \text { dengan } e=2 \mathrm{~mm} \\
& n=1 \text { (jumlah alur pulley) } \\
& B=(n-1) \cdot e+2 . e \\
& B=(1-1) \cdot 2+2 .(2) \\
& B=6 \mathrm{~mm}
\end{aligned}
$$

\section{Perencanaan Poros}

Pertimbangan yang digunakan untuk perencanaan poros sebagai berikut: [4]

a. Momen yang terjadi pada poros dapat dihitung sesuai dengan

$T=9,74 \times 10^{5} \cdot \frac{P_{d}}{n_{2}}$

Daya yang digunakan adalah $1 \mathrm{Hp}=746$ watt $=$ $0,746 \mathrm{~kW}$

$T=9,74 \times 10^{5} \cdot \frac{0,746 \mathrm{~kW}}{1400 \mathrm{rpm}}$

$$
T=518.1 \mathrm{~kg} \cdot \mathrm{mm}=5080 \mathrm{~N} \cdot \mathrm{mm}
$$

b. Tegangan geser yang diijinkan dapat dihitung sesuai dengan:

$$
\begin{aligned}
\tau_{a} & =\frac{\sigma_{b}}{\left(S f_{1} \times S f_{2}\right)} \\
\tau_{a} & =\frac{490 \frac{\mathrm{N}}{\mathrm{mm} 2}}{6 \times 3} \\
\tau_{a} & =27,22 \mathrm{~N} / \mathrm{mm}^{2}
\end{aligned}
$$

c. Diameter Poros dapat dihitung sesuai dengan

$$
\begin{aligned}
& d_{s}=\left[\frac{5,1}{\tau_{a}} \cdot K_{t} \cdot C_{b} \cdot T\right]^{\frac{1}{3}} \\
& d_{s}=\left[\frac{5,1}{27,22 \frac{\mathrm{N}}{\mathrm{mm}^{2}}} \times 5 \times 2,3 \times 5080 \mathrm{~N} . \mathrm{mm}\right]^{\frac{1}{3}}
\end{aligned}
$$




$$
\begin{aligned}
& d_{s}=\left[0,1873 \frac{\mathrm{mm}^{2}}{\mathrm{~kg}} \times 5 \times 2,3 \times 5080 \mathrm{~N} . \mathrm{mm}\right]^{\frac{1}{3}} \\
& d_{s}=\sqrt[3]{10942 \mathrm{~mm}^{3}} \\
& d_{s}=22,20 \mathrm{~mm}=0,87 \text { inch }=22 \mathrm{~mm}
\end{aligned}
$$

\section{Perencanan Daya Motor}

Data awal:

$$
\begin{array}{ll}
\mathrm{M} & =6,7 \mathrm{~kg} \\
\mathrm{~S} & =230 \mathrm{~mm}
\end{array}
$$

Daya motor yang digunakan adalah $=\frac{T \times n}{5252}$

$\mathrm{F} \quad=\mathrm{m} \cdot \mathrm{g}=6,7 \mathrm{~kg} \cdot 10^{\mathrm{m} / \mathrm{s}}=67 \mathrm{~N}$

$\mathrm{T} \quad=\mathrm{F} . \mathrm{s}=67 \mathrm{~N} \cdot 0,23 \mathrm{~m}=15,41 \mathrm{Nm}$

$\mathrm{HP}=\frac{T x n}{5252}=\frac{15,41 \mathrm{Nm} \times 326,6 \mathrm{rpm}}{5252}=0,95 \mathrm{HP}$

Jadi motor yang digunakan 1 HP (sesuai dipasaran)

\section{Material Rangka}

Material yang digunakan untuk perencanaan rangka alat penyortir beras menggunakan material St 37 dengan tegangan geser sebesar 360-440 N/m² (Niemann G, 1992). Sehingga untuk mengetahui material tersebut aman atau tidak, dapat dihitung dengan: [5], [6]

Tegangan geser material $\left(\sigma_{\text {material }}\right)=380 \mathrm{~N} / \mathrm{mm}^{2}=$ $380.10^{6} \mathrm{~N} / \mathrm{m}^{2}$

Faktor keamanan material $(s f)=5$ (terdapat beban kejut pada material dari putaran poros engkol).

$\sigma_{\mathrm{ijin}}=\frac{\tau \text { material }}{s f}=\frac{380.10^{6} \mathrm{~N} / \mathrm{m}^{2}}{5}=76.10^{6} \mathrm{~N} / \mathrm{m}^{2}$

\section{Hasil Perancangan}

Pada Gambar 2 berikut hasil perancangan dan pembuatan alat

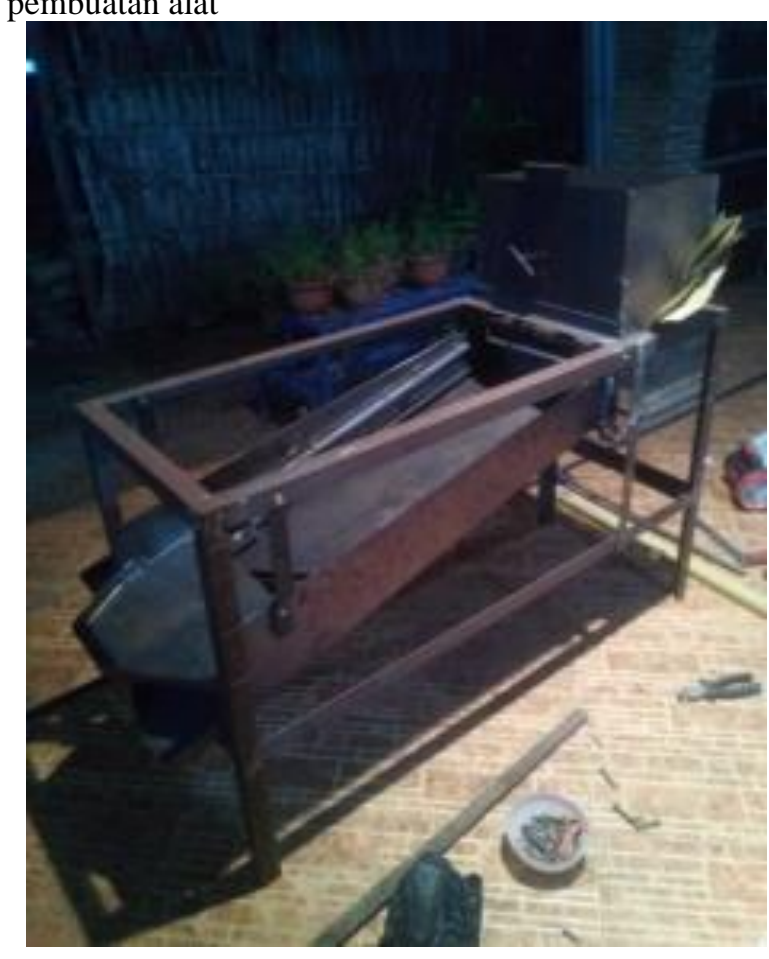

Gambar 2. Hasil Perancangan Alat
Berdasarkan Gambar 3 metode penyortir beras dilakukan melalui wadah penampung, proses penyortiran terjadi akibat adanya putaran poros engkol yang menggerakkan ayakan maju mundur, sehingga beras akan keluar berbeda beda. Komponen pendukung pada alat penyortir beras meliputi pulley, V-belt, bearing duduk dan poros sebagai media penyalur tenaga yang dihasilkan oleh motor listrik, seperti pada Gambar 3

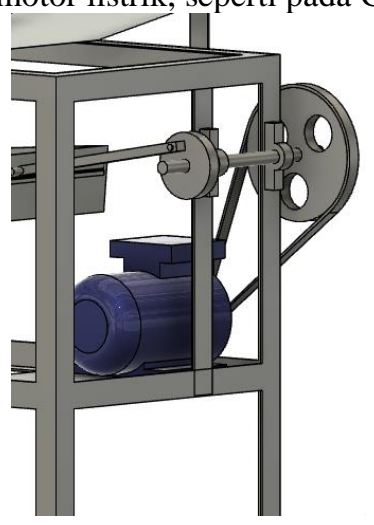

Gambar 3. Komponen Pendukung Alat

Konstruksi yang dirancang dan dibuat pada pada alat ini memiliki spesifikasi mesin yang ditunjukkan pada Tabel 1

\begin{tabular}{|l|l|} 
Tabel 1. Spesifikasi mesin \\
\hline Spesifikasi & Mesin Penyortir Beras \\
\hline Jenis Penggerak & $\begin{array}{l}\text { Motor listrik AC 1 HP pada } \\
\text { putaran 1400 rpm }\end{array}$ \\
\hline Sistem Transmisi & Pulley dan v-belt \\
\hline Dimensi Mesin (mm) & $\begin{array}{l}\mathrm{P}=790 \mathrm{~mm}, \mathrm{~L}=400 \mathrm{~mm}, \mathrm{~h}=815 \\
\mathrm{~mm}\end{array}$ \\
\hline Rangka Utama & Baja profil L, U, dan square \\
\hline Konsep Mesin & $\begin{array}{l}\text { Untuk penyortir beras utuh dan } \\
\text { tidak utuh }\end{array}$ \\
\hline
\end{tabular}

\section{Hasil Uji Coba Alat}

Berikut pada Tabel 2 dan Tabel 3, hasil uji coba alat dan dengan manual

\begin{tabular}{|c|l|c|c|c|c|c|}
\multicolumn{7}{|c|}{ Tabel 2. Hasil Uji Coba Alat } \\
\hline No & $\begin{array}{c}\text { Variasi } \\
\text { Sudut }\end{array}$ & $\begin{array}{c}\text { Waktu } \\
(\mathrm{s})\end{array}$ & $\begin{array}{c}\text { Beras } \\
\text { Utuh } \\
(\mathrm{Kg})\end{array}$ & $\begin{array}{c}\text { Beras } \\
\text { Murni } \\
(\%)\end{array}$ & $\begin{array}{c}\text { Beras } \\
\text { Campuran } \\
(\mathrm{Kg})\end{array}$ & $\begin{array}{c}\text { Menir } \\
(\mathrm{Kg})\end{array}$ \\
\hline 1 & $10^{\circ}$ & 5.08 & 8.40 & 85 & $0.58+1.20$ & 1.02 \\
\hline 2 & $15^{\circ}$ & 3.53 & 8.06 & 69 & $0.90+2.50$ & 1.04 \\
\hline
\end{tabular}

Tabel 3. Hasil Penyortiran Beras secara Manual

\begin{tabular}{|c|c|c|c|c|c|}
\hline No. & $\begin{array}{c}\text { Waktu } \\
\text { (Menit) }\end{array}$ & $\begin{array}{c}\text { Beras } \\
\text { Utuh } \\
(\mathrm{Kg})\end{array}$ & $\begin{array}{c}\text { Beras } \\
\text { murni } \\
(\%)\end{array}$ & $\begin{array}{c}\text { Beras } \\
\text { Campuran } \\
(\mathrm{Kg})\end{array}$ & $\begin{array}{c}\text { Beras } \\
\text { Menir (Kg) }\end{array}$ \\
\hline 1. & 7.59 & 8.9 & 85 & 2.50 & 1.1 \\
\hline
\end{tabular}

Prosentase keberhasilan alat dalam menyortir beras murni dapat dihitung sebagai berikut :

Beras murni pada sudut $10^{\circ}$

$$
\begin{aligned}
\text { Prosentase }= & \frac{\text { beras utuh tersortir }}{\text { beras utuh sudut } 10^{\circ}} \times 100 \% \\
& =\frac{7.2 \mathrm{~kg}}{8.40 \mathrm{~kg}} \times 100 \% \\
& =86 \%
\end{aligned}
$$


Beras murni pada sudut $15^{\circ}$.

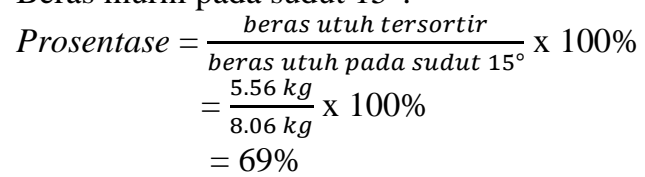

\section{Kesimpulan}

Dari penelitian didapatkan kesimpulan yang berisi tentang rancang bangun penyortir beras.

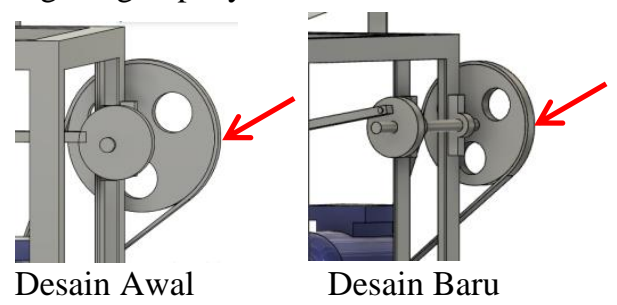

Dalam perancangan desain awal pada rancang bangun penyortir beras dalam menggerakkan mesh/ayakan menggunakan sistem vibrator sebagai getaran. Pada sistem vibrator menimbulkan getaran pada kerangka. Agar tidak menimbulkan getaran pada kerangka membuat perancangan desain baru dengan sistem poros engkol yang bergerak secara sleding. Untuk pemilihan perancangan desain yang tidak menimbulkan getaran pada kerangka menggunakan desain yang baru yaitu poros engkol serta adanya variasi dua sudut yaitu $10^{\circ}$ dan $15^{\circ}$ dengan kapasitas $10 \mathrm{~kg}$. Pada sudut $15^{\circ}$ didapatkan beras murni $69 \%$ dengan hasil kurang maksimal karena kemiringan sudut terlalu curam. Sedangkan pada sudut $10^{\circ}$ didapatkan hasil beras murni $85 \%$ yang mempunyai kemiringan sudut lebih minim sehingga penyortiran beras lebih maksimal.

\section{Daftar Rujukan}

[1] A. Yanto, “Analisa Unjuk Kerja Pengayak Getar Sebagai Sistem Getaran Dua Derajat Kebebasan Terhadap Pengayakan Abu Sekam Padi," Jurnal Momentum, vol. 15, no. 2, pp. 1-5, 2013.

[2] Irfandi, F. Sutrisno, E. Eswanto, and Jufrizal, “Analisa Uji Kinerja Mesin Pengayak Pasir Menggunakan Piringan Ayak dengan Metode Gerak Eksentrik Kapasitas 1 M3/Jam," vol. 3, no. 1, pp. 7-15, May 2017.

[3] Sularso and K. Suga, Dasar Perencanaan dan Pemilihan Elemen Mesin. Jakarta: Pradnya Paramita, 2004.

[4] A. Sateria et al., "Rancang Bangun Mesin Pengayak Pasir Untuk Meningkatkan Produktivitas Pengayakan Pasir Pada Pekerja Bangunan," Manutech : Jurnal Teknologi Manufaktur, vol. 11, no. 01, pp. 8-13, 2019, doi: 10.33504/manutech.v11i01.90.

[5] T. Wildi, Electrical Machines, Drives, and Power Systems, 6th ed. NJ: Pearson Prentice Hall, 2016.

[6] Sularso, Elemen Mesin. Jakarta: Pradya Paramitha, 1997. 